\title{
1 Cannibalistic attack by Octopus vulgaris in the wild: behaviour of 2 predator and prey
}

3

4

5

6

7

8

9

10

11

12

13

14

15

16

17

18

19

20

21

22

23

24

25

26

27

28

29

30

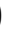

1

2

3
Jorge Hernández-Urcera ${ }^{1}$, Miguel Cabanellas-Reboredo ${ }^{2}$, Manuel E. Garci ${ }^{1}$, Jason Buchheim $^{3}$, Shane Gross ${ }^{4}$, Angel Guerra ${ }^{1}$ and David Scheel ${ }^{5}$

${ }^{1}$ Department of Ecology and Marine Resources, Instituto de Investigaciones Marinas (CSIC), Eduardo Cabello 6, 36208 Vigo, Spain;

${ }^{2}$ Balearic Oceanographic Center, Spanish Institute of Oceanography (IEO), 07015, Mallorca, Spain;

${ }^{3}$ Odyssey Expeditions, FL 34689, Florida, USA; ${ }^{4}$ Shane Gross Photography, Bahamas, USA; and

${ }^{5}$ Institute of Culture and the Environment, Alaska Pacific University, AK 99508, Anchorage, USA

Running head: RESEARCH NOTE

Correspondence: J. Hernández-Urcera; e-mail: jurcera@iim.csic.es 
31 Cannibalism refers to consuming a conspecific and is common in many taxa. In addition

32 o conferring advantages for a predator's growth, reproductive efficiency and survival

33 (e.g. elimination of future competitors, ready supply of high quality nutrition and of

34 optimal proportions of vitamins, minerals and amino acid), cannibalism is an important

35 link between individual and population-level processes (Claessen et al., 2002). Based

36 primarily on the study of stomach contents, Ibañez \& Keyl (2010) have shown that

37 cannibalism is widespread in cephalopods. Cannibalism thus potentially may be an

38 important component of natural mortality (Claessen, De Roos \& Persson, 2004), and

39 natural mortality is a key factor in the limitation of populations and management of

40 exploited resources. Cannibalism in octopuses has been recorded only infrequently

41 (Ibañez \& Keyl, 2010), and available anecdotal observations of cannibalism in the wild

42 are confined sexual cannibalism (e.g. Hanlon \& Forsythe, 2008; Huffard, Caldwell \&

43 Boneka, 2010; Huffard \& Bartick, 2014).

44 The common octopus, Octopus vulgaris Cuvier 1797, is exploited in the Mediterranean

45 Sea, the central and northeast Atlantic Ocean (O. vulgaris sensu stricto, Jereb et al.,

46 2014), as well as along the coasts of the Caribbean (O. "vulgaris” type I), Brazil (type

47 II), South Africa (type III) and Japan (type IV). To our knowledge, cannibalistic attack

48 behaviour has never been documented in the wild for this species. Improved knowledge

49 of this behaviour is important for understanding the ecology of this species and its

50 management. Here, we report on two separate observations of attacks made by $O$.

51 "vulgaris" type I on conspecifics in Caribbean coral reefs. Our observations were made

52 while snorkelling and SCUBA diving on two different reefs, with observers remaining

53 at some distance from the octopuses under study, so as not to disturb their natural

54 behaviour. 

on a shallow Caribbean coral reef off a headland in St Vincent $\left(13^{\circ} 12^{\prime} 51.30^{\prime \prime} \mathrm{N}\right.$, $61^{\circ} 16^{\prime} 38.12^{\prime \prime} \mathrm{W}$, St Vincent and the Grenadines), on 20 July 2014, at $2 \mathrm{~m}$ depth and 25

${ }^{\circ} \mathrm{C}$ bottom temperature. Observations were made while snorkelling and photographs were taken using a Sigma DP3 camera. Initially, an adult octopus was seen exploring the reef, when a much smaller, juvenile conspecific octopus appeared in the right visual field of the larger animal. The adult then chased the juvenile and the latter zigzagged around the reef, evading capture. The adult octopus nearly caught the juvenile, but the latter escaped by releasing a stream of ink and jetting very swiftly towards the water surface. While in pursuit, the adult octopus kept the prey in its right visual field through its body movements (J. Buchheim, personal observation). The adult octopus moved quickly towards the juvenile at the surface, keeping the first right arm in an advanced position; the adult then suddenly swept the first right arm and grabbed the juvenile octopus, which expelled a whitish substance. The large octopus engulfed the juvenile in its arms and web, following which it swam with its prey to the bottom of the reef, where it changed its body pattern.

72 S1) occurred on a shallow coral reef at 2 m-depth on the lee of Man Island, north of 73 Harbour Island in North Eleuthera $\left(25^{\circ} 32^{\prime} 22.32^{\prime \prime} \mathrm{N}, 76^{\circ} 38^{\prime} 27.17^{\prime \prime} \mathrm{W}\right.$, Bahamas $)$ on 13 74 July 2015 . The bottom temperature was $28^{\circ} \mathrm{C}$. Using a Nikon D90 camera, SCUBA 75 divers recorded the behaviour of octopuses while they foraged during the day. The 76 divers encountered an adult octopus with a disruptive (high contrast) body pattern 77 consisting of pale eyes, dark face, reticulated web and mantle blotches (Leite \& Mather, 78 2008). The octopus was seen inserting its anterior arms into the holes of a rock in the 79 coral reef. A juvenile $O$. "vulgaris" type I emerged from the rock in the right visual 
field of the adult and jetted backwards, away from the rock. The adult octopus chased the juvenile; the former adopted a uniform body pattern on leaving the substrate and like the juvenile, jetted backwards. While continuing to jet backwards, the fleeing juvenile suddenly changed its trajectory. In response, the adult interrupted its backward jet, spread its arms and suddenly reached out with the second right arm. Using a forward jet, the adult octopus then immediately attempted a second arm sweep with the first right arm. In response to each of these attempts by the adult, the juvenile inked and altered its trajectory. Following its second inking effort (Fig. 1A), the juvenile jetted vigorously towards the surface (Fig. 1B); the adult meanwhile paused momentarily and made contact with the substrate using all its arms except the first right arm. The adult then jetted forward just above the substrate, following the fleeing juvenile octopus and expanding its mantle to its fullest extent while it did so (Fig. 2A, B). The adult octopus then jetted and extended its first right arm swiftly up towards the fleeing juvenile (Fig. 2C, D) and using this arm made contact with the juvenile (Fig. 1C). Finally, the adult octopus twisted its first right arm, apparently in an attempt to encircle the juvenile (Fig. 2E, F).

During pursuit and capture, the adult octopus kept the juvenile in its right visual field, by switching from backward to forward jetting when the fleeing juvenile abruptly changed trajectory. Following the moment of contact with the juvenile, the adult began to raise the second right and first left arms, and to spread its remaining arms and web, which caused a rapid deceleration. At this moment, the juvenile was apparently restrained only by the first right arm of the adult, which was twisted once around one of the arms of the juvenile. The adult then pulled its first right arm, with the prey, towards its mouth (Fig. 2G). At the same time the adult crossed its first left arm over its first right and brought its second left arm along the ventral side of the first right arm; this 
ensured that both additional arms made contact with the juvenile as the prey was pushed

106 toward the adult's mouth (Fig. 1D). The first right arm of the adult almost immediately emerged from near the mouth; all arms were then brought together about midway along their lengths. The juvenile was thus engulfed within the adult's arms and web. The adult octopus subsequently jetted directly to the substrate and adopted a mottled body pattern. To our knowledge, the cannibalistic attack behaviour described here for wild

111 Octopus vulgaris has not been observed before. Although some details of presumed 112 cannibalistic behaviour have been reported by Hernández-Urcera et al. (2014) for this 113 species, the octopuses preyed on were dead when first encountered by the authors. It is 114 also unclear if these preliminary observations were of active cannibalism (Heinen \& 115 Abdella, 2005) or of living octopuses feeding on dead animals. The two records 116 presented here each describe the encounter, pursuit and capture of a smaller, juvenile 117 octopus by a larger (adult) octopus, with the predator making repeated attempts to 118 capture the prey. In both of the attacks, the predator was observed to extend an anterior arm

120 towards the prey and make contact with the prey. Just prior to the second observed 121 attack, the first right arm of the adult was advanced, suggesting that the predator may 122 have anticipated using that arm for prey capture. The unusual crossing of the first left 123 arm over the first right arm in combination with the recruitment of the second right arm 124 apparently enabled the adult to increase contact with the prey, which had been poorly 125 restrained up to that point. A similar complex crossing of octopus arms has been 126 observed in Octopus tetricus (D. Scheel et al., unpublished data), but this not been 127 described as a means of restraining prey in octopus ethograms (e.g. Mather, 1998; 128 Mather \& Alupay, 2016). 
130 behaved in a similar way. Both juveniles attempted to escape by inking and jetting;

131 these are secondary antipredator defences used in response to a threat (Hanlon \&

132 Messenger, 1996; Huffard, 2006). Also, both prey octopus fled toward the surface of the

133 water, despite the increased vulnerability that comes with moving in the water column.

134 The behaviour of fleeing towards the water surface has also been observed in Octopus

135 cyanea, but only after mating (Hanlon \& Forsythe, 2008); a smaller male successfully

136 escaped towards the surface when pursued by a female that did not leave the substrate.

137 Escaping toward the surface is certainly risky for the prey. It may also may be risky for

138 the predator, and this may potentially explain why the prey may use this as a last resort

139 when attempting to escape from predators.

Although the predatory and escape responses of octopuses are complex, the

141 similarities noted in the two episodes of cannibalistic attack described here suggest that

142 simpler patterns may underlie the complexity. More broadly, these observations suggest

143 inter-cohort cannibalism in octopuses may be as common as sexual cannibalism.

\section{ACKNOWLEDGMENTS}

145 We especially thank Laura Iglesias for providing the octopus illustrations used in Figure

146 2. We also thank Dr Álvaro Roura and Dr Manuel Nande for their valuable comments

147 and suggestions. Jorge Hernández-Urcera and Miguel Cabanellas-Reboredo were

148 supported by two Juan de la Cierva's post-doc research grants (\# FJCI-2016-30990 and

149 \# FJCI-2014-20374, respectively) funded by the Spanish Ministry of Science,

150 Innovation and Universities.

\section{REFERENCES}


CLAESSEN, D., VAN OSS C., DE ROOS A.M. \& PERSSON, L. 2002. The impact of size-dependent predation on population dynamics and individual life history. Ecology, 83: 1660-1675.

CLAESSEN, D., DE ROOS A.M. \& PERSSON, L. 2004. Population dynamic theory of size-dependent cannibalism. Proceedings of the Royal Society of London Series B, 271: 333-340.

HANLON, R.T. \& MESSENGER, J.B. 1996. Cephalopod Behaviour. Cambridge University Press, Cambridge.

HANLON, R.T. \& FORSYTHE, J.W. 2008. Sexual cannibalism by Octopus cyanea on a Pacific coral reef. Marine and Freshwater Behaviour and Physiology, 41: 19-28.

HEINEN, J.T. \& ABDELLA, J.A. 2005. On the advantages of putative cannibalism in american toad tadpoles (Bufo a. americanus): is it active or passive and why? American Midland Naturalist, 153: 338-347.

HERNÁNDEZ-URCERA, J., GARCI, M.E., ROURA, A., GONZÁLEZ, A.F., CABANELLAS-REBOREDO, M., MORALES-NIN, B. \& GUERRA, A. 2014. Cannibalistic behaviour of Octopus vulgaris in the wild. Journal of Comparative Psychology, 128: 427-430.

HUFFARD C.L. 2006. Locomotion by Abdopus aculeatus (Cephalopoda: Octopodidae): walking the line between primary and secondary defenses. Journal of Experimental Biology, 209: 3697-3707.

HUFFARD, C.L., CALDWELL, R.L. \& BONEKA, F. 2010. Male-male and malefemale aggression may influence mating associations in wild octopuses (Abdopus aculeatus). Journal of Comparative Psychology, 124: 38-46.

HUFFARD, C.L. \& BARTICK, M. 2014. Wild Wunderpus photogenicus and Octopus cyanea employ asphyxiating 'constricting' in interactions with other octopuses. Molluscan Research, 35: 1-5.

IBAÑEZ C.M. \& KEYL, F. 2010. Cannibalism in cephalopods. Reviews in Fish Biology and Fisheries, 20: 123-136.

JEREB, P., ROPER, C.F.E., NORMAN, M.D. \& FINN J. 2014. Cephalopods of the world. An annotated and illustrated catalogue of cephalopod species known to date. Volume 3. Octopods and Vampire Squids. FAO Species Catalogue for Fishery Purposes. FAO, Rome.

LEITE, T. \& MATHER, J.A. 2008. A new approach to octopuses' body pattern analysis: a framework for taxonomy and behavioral studies. American Malacological Bulletin, 24: 31-41.

MATHER, J.A. 1998. How do octopuses use their arms? Journal of Comparative Psychology, 112: 306-316.

MATHER, J.A. \& ALUPAY J.S. 2016. An ethogram for benthic Octopods (Cephalopoda: Octopodidae). Journal of Comparative Psychology, 130: 109-127. 
194 Figure 1. Behaviour of predator and prey during the cannibalistic attack in North

195 Eleuthera (Bahamas). A. Juvenile octopus has begun jetting towards the surface of the 196 water, while ejecting ink (white ellipse). B. Adult octopus with first right arm in an 197 advanced position. C. Adult 'catapulting' first right arm towards the juvenile. D. On 198 capturing the juvenile, adult tucks first right arm orally, while it holds an arm of the 199 prey octopus; first left arm of adult is in the process of being crossed over the first right 200 arm.

201

Figure 2. Sequence of movements of the first right arm of the female Octopus vulgaris during the cannibalistic attack in North Eleuthera (Bahamas). A. Arm in an advanced position. B. Proximal part of the arm slightly raised and bend in arm angled towards the prey. C. Distal end of arm extended towards prey. D, E. Further extension of arm and contact with an arm of the prey. F. Arm rotated on itself, with distal tip encircling an arm of the prey. G. Arm holding prey bent orally and shortened.

\section{9}
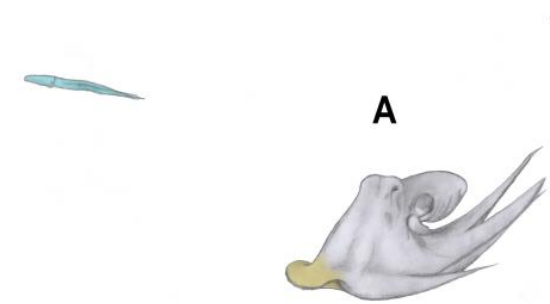

213

214

215

216

217

218

219

220

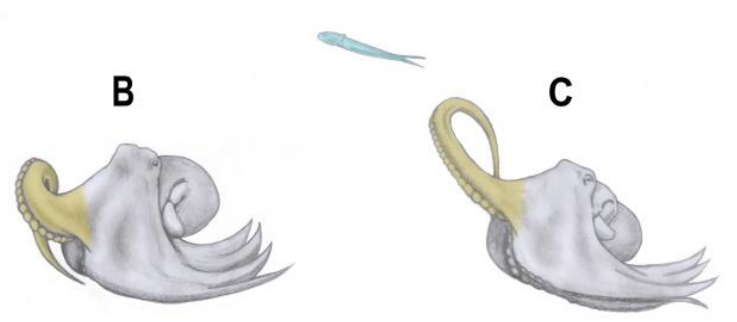



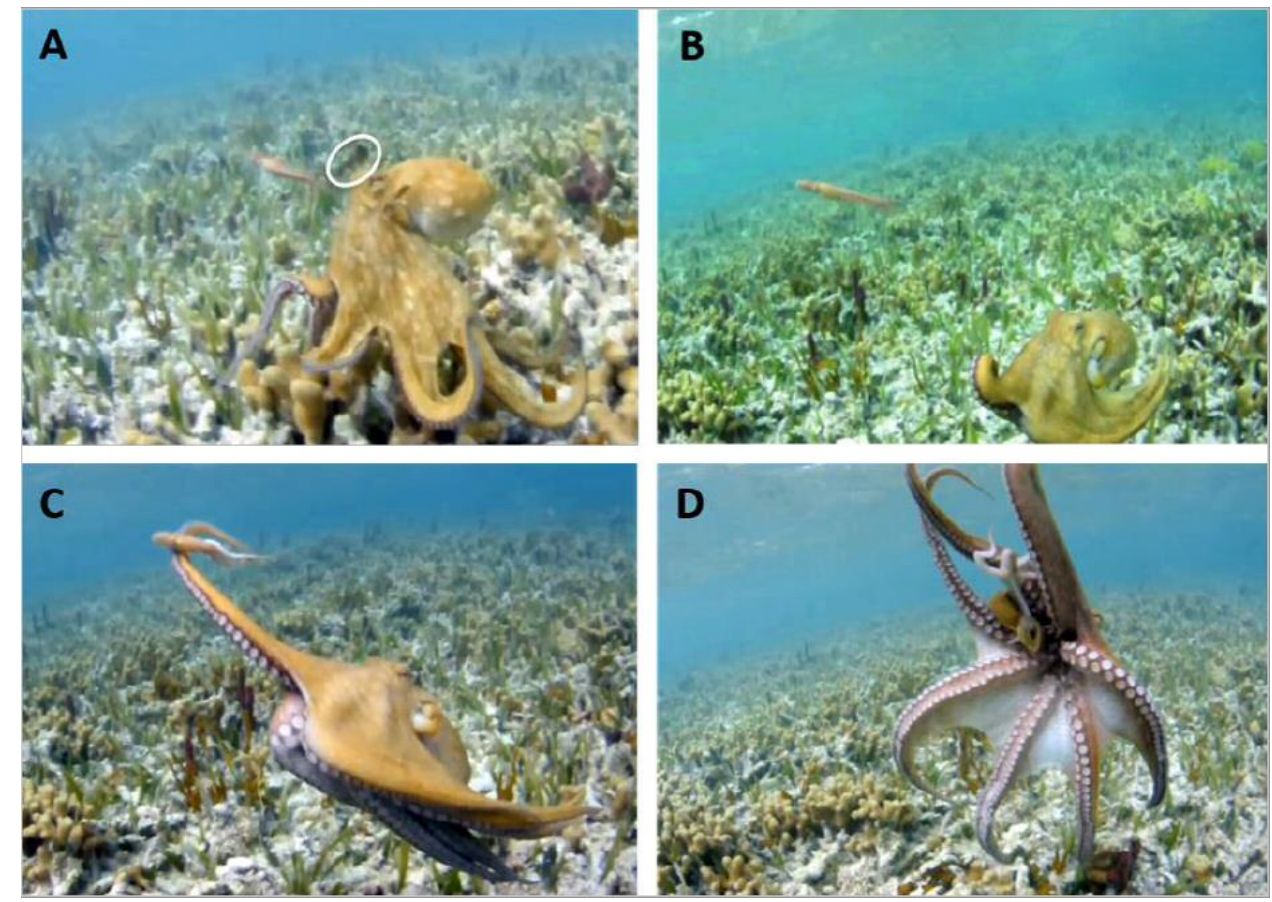